\title{
@ (0) \\ Re: Simplified Fournier's gangrene severe index score (SFGSI)
}

\author{
Sora Yasri ${ }^{1}$, Viroj Wiwanitkit ${ }^{2}$ \\ ${ }^{1}$ KMT Primary Care Center, Bangkok Thailand; ${ }^{2}$ Hainan Medical University, China
}

To the editor,

We read the publication on "Risk factors for mortality in Fournier's gangrene in a general hospital: use of simplified Fournier's gangrene severe index score (SFGSI)" with great interest (1). Tenório et al. concluded that "The main advantage is easy applicability because it contains only three parameters and can be used immediately after patient's admission" (1). Indeed, as noted by Yeniyol et al., "Patients' metabolic status and the extent of disease at presentation is an important factor in the prognosis of Fournier's gangrene" (2). There are some concerns on this report. First, the score cannot be immediately used; it has to wait for gathering the information if there is no pre-admission complete clinical history and laboratory data. Second, the mentioned variables are also affected by other possible concomitant disorders. For example, hemoglobin can be affected by any inherited and non -inherited anemic disorders.

\section{REFERENCES}

1. Tenório CEL, Lima SVC, Albuquerque AV, Cavalcanti MP, Teles F. Risk factors for mortality in fournier's gangrene in a general hospital: use of simplified founier gangrene severe index score (SFGSI). Int Braz J Urol. 2018;44:95-101.

2. Yeniyol CO, Suelozgen T, Arslan M, Ayder AR. Fournier's gangrene: experience with 25 patients and use of Fournier's gangrene severity index score. Urology. 2004;64:218-22.

Submitted for publication:

October 2, 2017

Accepted after revision:

October 15, 2017

Published as Ahead of Print:

October 30, 2017
Correspondence address:

Sora Yasri, MD

KMT Primary Care Center

Bangkok Thailand

E-mail: soryasri@outlook.co.th

ARTICLE INFO

Int Braz J Urol. 2018; 44:204-204 